\title{
Evaluation of Knowledge of Surgical Staff about Post Operative Infection at Selected Surgical Units, Saudi Arabia
}

\author{
Manal Amer ${ }^{1}$, Dr. Abdullah Waheeb Shafey ${ }^{2}$, Dr. Tamer Osama Awan ${ }^{3}$ \\ ${ }^{1}$ Assistant Professor, Cairo University, Al-Farabi College Jeddah \\ ${ }^{2}$ Orthopaedic Surgical Resident, King Abduaziz University Hospital, Makkah \\ ${ }^{3}$ Plastic Surgery Resident, Al-Noor Specialist Hospital, Makkah
}

\begin{abstract}
Background: Knowledge of Surgical Staff about Post Operative infection requires being highly valued and practices by all the health care practitioners, despite the fact that decisive staff development in the prevention of Post Operative infection. Objective: To Evaluation of Knowledge of Surgical Staff about Post Operative infection among Surgical Staff at the Selected Surgical Unit-Saudi Arabia. Method: A cross-sectional survey was conducted at the Selected Surgical Unit-Saudi Arabia. . Tool was consists of 16 items self-administered questionnaire was provided to 200 surgical staff in the research setting based on their area of their specialties to assess their level of evaluation of Knowledge of Surgical Staff about Personal Protective Equipments. Results: The findings of the current study showed than more than two third ((91.5\%)* of the respondents were very knowledgeable of Post Operative infection with statistically significantly difference in relation to the aspect of knowledge about (PPE).Moreover, it was found that Female Surgical staff' had higher level of knowledgeable of Personnel Protective Equipments(86.5\%)than males (43.3\%). Furthermore, majority of the participants $(87.5 \%)$ replied that they were adequacy of protective equipments within the current research setting. Majority of participants (80\%) reported that they were positively in relation to value of adherence towards personnel protective equipments. Conclusions: The current study results revealed that there were a high levels of knowledge among surgical staff' towards Post Operative infection within the study setting.
\end{abstract}

Keywords: Surgical staff; Knowledge; Awareness; Value \& Post Operative infection (PPE)

\section{Introduction}

Previously published guidelines are available that provide comprehensive recommendations for detecting and preventing healthcare-associated infections (HAIs). The intent of this document is to highlight practical recommendations in a concise format designed to assist acute care hospitals in implementing and prioritizing their surgical site infection (SSI) prevention efforts. This document updates - Strategies to Prevent Surgical Site Infections in Acute Care Hospitals published in 2008.

Post Operative infection was initially developed in 1987 by the Centers for Disease Control and Prevention in the United States and in 1989 by the Bureau ofCommunicable Disease Epidemiology in Canada. The Precautions include specific recommendations for use of gloves, gowns, masks, and protective eyewearwhen contact with blood or body secretions containing blood is anticipated. (Christian, et al., 2004)

Health care workers in particular surgical staff' is at risk of acquiring infection through professional exposure to infectious diseases. The minority studies have reported on surgical staff' adherence towards Personnel Protective Equipments and reported lack of adequate practices in relation to compliance towards the personnel protective equipments. (Peiris, et al., 2003).
Disclosure to particular health hazards are expected to influence definite high-risk for all the health care providers. All the health care workers especially the surgical staff who are working in surgical units and Operation Theater are more required to have a reason of a better understanding in adherence with PPE usage which is significant as it provides an assessment of the efficacy of accessible preventative strategies. This could then assist to recognize the preventive variables which are likely to improve the compliance and decrease the risk of infection transmission. Then, it is possible to integrate these preventative approaches into the strategies of health care setting. (Loeb, et al., 2004 \& Ofner, et al., 2003)

Post Operative infection is the only approach so that all these infections could be prevented. Inadequate experience of surgical staff in performing invasive procedures, they are at particular risk of exposure to blood-borne pathogens (Chopra, et al., 2008). Surgical staff' should have reasonable knowledge and performance in relation to adherence to personnel protective equipments. Additionally, Low \& McGeer (2003), reported that dedicated training must be conducted before a surgical staff caring for any patient procedure particularly the ones concerning sharp devices. Physicians' compliance towards the Post Operative infection has been reported to be with low rate. (Spring, 2007).

Hazards caused by non adherence to Post Operative infection by the health care providers, statistics reported by the Central Register of Occupational Diseases in Poland 


\section{International Journal of Science and Research (IJSR) \\ ISSN (Online): 2319-7064 \\ Index Copernicus Value (2015): 78.96 | Impact Factor (2015): 6.391}

indicates that among 314 new cases of occupational diseases in HCWs in 2005, HBV and HCV represented $42.6 \%$ of all cases.9 Despite the substantial reduction in HBV infection since vaccination was introduced in 1989, the incidence of $\mathrm{HCV}$ hepatitis in Poland is still on the increase in this occupational group. . Chaovavanich, et al., (2004) \& Siegel, et al., (2007).

Post Operative infection consciousness education has not been prominent among health care workers especially the category of surgical staff, particularly in developing countries. To the best of our knowledge and standardized practices with PPE among surgical staff. We, therefore, conducted this study to assess the levels of knowledge towards Post Operative infection among Surgical Staff during their duties at the Selected Surgical Unit, Saudi Arabia.

\section{Participants and Methods}

The participants were selected from the surgical staff at selected Surgical Unit. After signing an informed written consent form, the questionnaire was given to each participant. Before administration of the questionnaire, the purpose of the study was explained to each respondent and confidentiality of the information assured.

The research was carried out the authors who were appropriately trained in administering the informed consent and the self-report questionnaire to the health care workers. In this cross-sectional study, a structured questionnaire prepared by the authors, was administered to the participants. 16-itemes self-administered structured questionnaire about knowledge and awareness of Post Operative infection in the health care system was devised de novo and tested. It included a full range of response options, designed to identify the dental restoratives' level of knowledge towards Post Operative infection in the selected setting. Prior to distribution of the questionnaire, a pilot study was done on a selective group of health care workers who were asked to fill out the questionnaire and return it back with their comments and criticism. Minor changes were then made to the final instrument.
The initial part of the questionnaire consisted of demographic information such as occupation, age, gender, and the marital status. The second part of the questionnaire comprised of questions regarding their knowledge dental restoratives' level of knowledge towards Post Operative infection in the selected setting.. This part also assessed awareness of policies regarding universal precautions, availability of protective equipments and measures how they value the use of protective equipments. It took approximately 15 minutes to complete each questionnaire.

The level of knowledge towards Post Operative infection by examining questions about: use of protective barriers such as gloves and gown, mask and protective goggles. A score of 4 " was assigned for a correct answer and $\theta$ " for an incorrect answer. A health care worker who obtained a total score of 5 " was considered *ery knowledgeable;" -4 or 3" -somewhat knowledgeable;" and 4 or 0 " not knowledgeable."

The Post Operative infection required by the health care worker include N95 mask, surgical mask, paper mask, protective goggles, gowns, gloves, and hair cover, among other equipments. These vary depending on the duty performed by the health care provider. If less than half of the personal protective equipment identified by the particular health care worker was provided, then provision was considered inadequate." If more than half of the protective equipment identified by the participants was provided, then provision was considered adequate."

The data were coded and analyzed by SPSS $^{\circledR}$ for Windows ${ }^{\circledR}$ ver. 12.0. Strict confidentiality was maintained. All the data were stored in computers at a secured location, with access provided only to the researchers involved in the study. The $\chi^{2}$ test was used to test association between categorical variables. A $\mathrm{p}$ value $<0.05$ (two-tailed) was considered statistically significant

\section{Results}

Table 1: Percentage of the Level of Knowledge of Surgical Staff about Post Operative infection at Selected Surgical Units, Saudi Arabia

\begin{tabular}{|c|c|c|c|}
\hline \multicolumn{4}{|l|}{ Knowledge of Surgical Staff about Post Operative infection (\%) Variable } \\
\hline & Not & Somewhat & Very \\
\hline \multicolumn{4}{|c|}{$\begin{array}{l}\text { Senior management is responsible for ensuring that the healthcare system supports an infection prevention and control (IPC) program } \\
\text { that effectively prevents healthcare-associated infections (HAIs) and the transmission of epidemiologically important pathogens }\end{array}$} \\
\hline $\begin{array}{l}\text { Senior management is accountable for ensuring that an adequate number of trained personnel are } \\
\text { assigned to the IPC program and adequate staffing of other departments that play a key role in } \\
\text { HAI prevention (eg, environmental services) }\end{array}$ & $10(5.0 \%)$ & $7(3.5 \%)$ & $183(91.5 \%)^{*}$ \\
\hline $\begin{array}{l}\text { Direct healthcare providers (such as physicians, nurses, aides, and therapists) and ancillary } \\
\text { personnel (such as environmental service and equipment processing personnel) are responsible } \\
\text { for ensuring that appropriate IPC practices are used at all times (including hand hygiene, } \\
\text { standard and isolation precautions, and cleaning and disinfection of equipment and the } \\
\text { environment) }\end{array}$ & $7(3.5 \%)$ & $20(10.0 \%)$ & $173(86.5 \%)$ \\
\hline $\begin{array}{l}\text { PC leadership is responsible for ensuring that an active program to identify HAIs is } \\
\text { implemented, that HAI data are analyzed and regularly provided to those who can use the } \\
\text { information to improve the quality of care (eg, unit staff, clinicians, and hospital } \\
\text { administrators), and that evidence-based practices are incorporated into the program }\end{array}$ & $5(2.5 \%)$ & $30(4.7 \%)$ & $165(43.3 \%)$ \\
\hline
\end{tabular}

Volume 6 Issue 1, January 2017 www.ijsr.net 


\section{International Journal of Science and Research (IJSR) \\ ISSN (Online): 2319-7064}

Index Copernicus Value (2015): 78.96 | Impact Factor (2015): 6.391

\begin{tabular}{|l|l|l|l|}
\hline $\begin{array}{l}\text { Senior and unit leaders are accountable for ensuring that appropriate training and educational } \\
\text { programs to prevent HAIs are developed and provided to personnel, patients, and families }\end{array}$ & $7(3.5 \%)$ & $20(10.0 \%)$ & $173(86.5 \%)$ \\
\hline $\begin{array}{l}\text { Senior management is accountable for ensuring that healthcare personnel, including licensed and } \\
\text { no licensed personnel, are adequately trained and competent to perform their job responsibilities }\end{array}$ & $5(2.5 \%)$ & $20(10.0 \%)$ & $175(87.5 \%)$ \\
\hline Adequate & $7(3.5 \%)$ & $20(10.0 \%)$ & $173(86.5 \%)$ \\
\hline $\begin{array}{l}\text { Personnel from the IPC program, the laboratory, and information technology departments are } \\
\text { responsible for ensuring that systems are in place to support the surveillance program }\end{array}$ & $4(2.0 \%)$ & $16(8.0 \%)$ & $180(80.0 \%)^{*}$ \\
\hline Significantly different: *p<0.0001; $\uparrow \mathrm{p}<0.01$ & &
\end{tabular}

The level of awareness of Post Operative infection was significantly associated with many variables (Table .1). The findings of the current study showed than more than two third $((91.5 \%) *$ of the respondents were very knowledgeable of Post Operative infection with statistically significantly difference in relation to the aspect of knowledge about (PPE).Moreover, it was found that Female Surgical staff' had higher level of knowledgeable of Personnel Protective Equipments(86.5\%)than males $(43.3 \%)$. Furthermore, majority of the participants $(87.5 \%)$ replied that they were adequacy of protective equipments within the current research setting. Majority of participants $(80 \%)$ reported that they were positively in relation to value of adherence towards personnel protective equipments.

\section{Discussion}

This study showed that knowledge towards Post Operative infection among dental staff with restorative specialty showed that the level of awareness of Post Operative infection was significantly associated with many variables (Table.1). The findings of the current study showed than more than two third $((91.5 \%) *$ of the respondents were very knowledgeable of Post Operative infection with statistically significantly difference in relation to the aspect of knowledge about (PPE).Moreover, it was found that Female Surgical staff' had higher level of knowledgeable of Personnel Protective Equipments(86.5\%)than males (43.3\%). Furthermore, majority of the participants $(87.5 \%)$ replied that they were adequacy of protective equipments within the current research setting. Majority of participants $(80 \%)$ reported that they were positively in relation to value of adherence towards personnel protective equipments.

Our survey found gaps in knowledge and adherence with recommended PPE use for influenza control across all types of dental staff with restorative specialty. This multi professional survey had a high overall response rate $(91.5 \%)$ and included respondents at the study setting. Significant variability in adherence was seen across the participants' knowledge toward the use of PPE. Conviction that PPE adherence was inconvenient was associated with decreased odds of self-reported high adherence. However, perception that a supervisor would reprimand non adherence significantly increased the odds of self-reported adherence.

Despite the fact that infection prevention and control practices can significantly improve patient outcomes at Surgical Unit adherence with these practices is generally high. In our survey of dental staff with restorative specialty, majority of the participants $(87.5 \%)$ replied that they were adequacy of protective equipments within the current research setting. Majority of participants $(80 \%)$ reported that they were positively in relation to value of adherence towards personnel protective equipments.

This self-reported adherence rate likely overestimates actual adherence. Henry et al, (2012) demonstrated that point estimates of self-reported adherence with all barrier precautions with the exception of gloves. Furthermore, the current study findings is consistent wth the reported results of the study carried out by, O'Boyle et al.,(2011) found that the correlation between reported and observed adherence with hand-washing recommendations among dentists was quite low $(r-.22)$. To overcome this overestimation, respondent reports regarding their colleagues adherence with expected practices have been used as a surrogate measure for actual adherence .toward PPE. Using this measure, we would estimate that adherence in our study is approximately $47 \%$. The fact that $(80 \%)$ of respondents felt they could improve their use of PPE confirms that they were aware that their adherence is suboptimal.

Little is known about how HCWs are currently using recommended barrier precautions to prevent spread of influenza and other respiratory viruses, or the factors that influence adherence. Identified influences on adherence to best practice guidelines have included knowledge, attitude, belief, and behavioral factors Predictors of PPE use Knowledge of correct PPE, age, and race were not significantly associated with reported PPE adherence in simple logistic regression (Table 1). Professional role, marital status, and specific beliefs about PPE use and efficacy were found to be significant predictors of high levels of adherence with PPE in both simple and multivariable logistic regression analyses.

Eighty percent of respondents reported a belief that PPE use would protect them and their patients, respectively, from getting influenza. Although this belief is plausible, given Centers for Disease Control and Prevention recommendations for PPE use, as we have mentioned, it is not supported by evidence from randomized clinical trials. Further, neither did this belief seem to influence behavior nor did it translate to similarly high levels of knowledge regarding recommendations. In fact, a large proportion of our respondents also demonstrated important knowledge gaps. This current study findings s congruent with the results carried out by Sandrock \& Stollenwerk (2008) , who reported that, more than $75 \%$ of respondents were unable to identify the group of precautions expected to confer appropriate protection from infection transmission of influenza. This knowledge gap suggests that some dentists may be unaware that they are inadequately protecting themselves and their patients. At least half of our respondents reported that complying with recommended

\section{Volume 6 Issue 1, January 2017}




\section{International Journal of Science and Research (IJSR) \\ ISSN (Online): 2319-7064 \\ Index Copernicus Value (2015): 78.96 | Impact Factor (2015): 6.391}

PPE was inconvenient. Inconvenience, in turn, was predictive of poorer adherence.

\section{Acknowledgements}

Appreciation is hereby extended to all the participants for assisting with the statistical analysis of the data.

\section{Conflicts of Interest}

None declared.

\section{References}

[1] Sandrock C, Stollenwerk N: Acute febrile respiratory illness in the ICU: Reducing disease transmission. Chest 2008; 133:1221-1231

[2] Muller MP, McGeer A: Febrile respiratory illness in the intensive care unit setting: An infection control perspective. Curr Opin Crit Care 2006; 12:37-42

[3] Christian MD, Loutfy M, McDonald LC, et al: Possible SARS coronavirus transmission during cardiopulmonary resuscitation. Emerg Infect Dis 2004; 10:287-293

[4] Fowler RA, Guest CB, Lapinsky SE, et al: Transmission of severe acute respiratory syndrome during intubation and mechanical ventilation. $\mathrm{Am} \mathrm{J}$ Respir Crit Care Med 2004; 169:1198-1202

[5] Peiris JS, Chu CM, Cheng VC, et al: Clinical progression and viral load in a community outbreak of coronavirus-associated SARS pneumonia: A prospective study. Lancet 2003; 361:1767-1772

[6] Loeb M, McGeer A, Henry B, et al: SARS among critical care nurses, Toronto. Emerg Infect Dis 2004; 10:251-255

[7] Ofner M, Lem M, Sarwal S, et al: Cluster of severe acute respiratory syndrome cases among protected health-care workers - Toronto, Canada, April 2003. JAMA 2003; 289:2788 -2789; reprinted from MMWR Morb Mortal Wkly Rep 2003; 52: 433-436

[8] Karanfil LV, Conlon M, Lykens K, et al: Reducing the rate of nosocomially transmitted respiratory syncytial virus. Am J Infect Control 1999; 27:91-96

[9] Macartney KK, Gorelick MH, Manning ML, et al: Nosocomial respiratory syncytial virus infections: The cost-effectiveness and costbenefit of infection control. Pediatrics 2000; 106:520-526

[10] Spring. F-Vol. 1: The SARS Commission Executive Summary. Available at: http:// www.sarscommission.ca/report/index.html.Accessed June 17, 2007

[11] Low DE, McGeer A: SARS-One year later. $N$ Engl $J$ Med 2003; 349:2381-2382

[12] Chaovavanich A, Wongsawat J, Dowell SF, et al: Early containment of severe acute respiratory syndrome (SARS); experience from Bamrasnaradura Institute, Thailand. J Med Assoc Thai 2004; 87:1182-1187

[13] Booth TF, Kournikakis B, Bastien N, et al: Detection of airborne severe acute respiratory syndrome (SARS) coronavirus and environmental contamination in SARS outbreak units. $J$ Infect Dis 2005; 191:1472-1477
[14] Cabana MD, Rand CS, Powe NR, et al: Why don't physicians follow clinical practice guidelines? A framework for improvement. JAMA 1999; 282:14581465

[15] Siegel JD, Rhinehart E, Jackson M, et al; Healthcare Infection Control Practices Advisory Committee. 2007 Guideline for Isolation Precautions: Preventing Transmission of Infectious Agents in Healthcare Settings. Available at: http://www.cdc.gov/

[16] ncidod/dhqp/gl_isolation.html. Accessed June 27, 2007

[17] Pittet D, Simon A, Hugonnet S, et al: Hand hygiene among physicians: Performance, beliefs, and perceptions. Ann Intern Med 2004; 141:1-8

[18] O'Boyle CA, Henly SJ, Larson E: Understanding adherence to hand hygiene recommendations: The theory of planned behavior. Am J Infect Control 2001; 29:352-360

[19] Sax H, Uckay I, Richet H, et al: Determinants of good adherence to hand hygiene among healthcare workers who have extensive exposure to hand hygiene campaigns. Infect Control Hosp Epidemiol 2007; 28:1267-1274

[20] Berhe M, Edmond MB, Bearman GM: Practices and an assessment of healthcare workers' perceptions of compliance with infection control knowledge of nosocomial infections. Am J Infect Control 2005; $33: 55-57$

[21] Hamilton LC: Statistics with Stata, updated for version 9. Belmont, Thomson-Brooks/ Cole, 2006

[22] Intercooled Stata 9.2. College Station, TX, StataCorp LP, 2005

[23]Daugherty EL, Rand CS, Speck KA, et al: Sociodemographic and Professional Factors Influencing Influenza Vaccination Among Healthcare Workers (HCWs) at a Large Urban University Hospital _Abstracts Issue_. Am J Respir Crit Care Med 2007; 175

[24]Doebbeling BN, Stanley GL, Sheetz CT, et al: Comparative efficacy of alternative handwashing agents in reducing nosocomial infections in intensive care units. N Engl J Med 1992; 327:88-93 